\title{
Armoedekultuur: Die leefwêreld van die Nuwe Testament en die situasie in Suid-Afrika vandag
}

\author{
Andries van Aarde \\ Departement Nuwe-Testamentiese Wetenskap (Afd A) \\ Universiteit van Pretoria
}

\begin{abstract}
Culture of poverty: The world of the New Testament then and the situation in South Africa today

In this article poverty in the world of the New Testament is explained in the light of the social dynamics of the first century Eastern Mediterranean. The focus is on the sub-culture of the disreputable poor. Features of a culture of poverty are reflected upon from a social-scientific perspective in order to try to understand why poverty is intensifying in South Africa today. The article aims at identifying guidelines for Christians in using the New Testament in a profound way to challenge the threat of poverty. The following aspects are discussed: the underdevelopment of third-world societies over against the technical evolution in first-world societies during the past two hundred years, economic statistics with regard to productivity and unemployment in South Africa, the social identity of the disreputable poor, poverty within the pre-print culture of the biblical period, and the church as the household of God where Christians should have compassion for others.
\end{abstract}

\section{INLEIDING}

'n Lesing soos hierdie kan bloot beskrywend wees of dit kan beskrywend én verduidelikend wees. Die eersgenoemde benadering kan bestaan uit eerstens die identifisering en semantiese definiëring van die Griekse woorde, uitdrukkings en begrippe wat in die Nuwe Testament op armoede betrekking het en tweedens die opnoem en die eksegese van die passasies in die Nuwe Testament wat met armoede verband hou.

* Voordrag gelewer op 22 September 1995 tydens 'n simposium van lidmate van die Hervormde Kerk in Suidelik Afrika en die Nederduitsch Hervormde Kerk van Afrika by die Universiteit van Pretoria, gereël deur die Sentrum vir Teologiese Navorsing en Toerusting (Fakulteit Teologie, Afd A) en die Raad vir Ekumeniese Sake (NHKA). 
Ek gaan nie hierdie benadering in my voordrag volg nie, want die bedoeling van die simposium is dat ons nie net meer van die verskynsel van armoede in ons midde bewus sal word nie, maar ook weë sal soek hoe Christene - mense wat riglyne vir gecindheid en opstrede in daaglikse situasies graag in die Bybel vind - die probleem van armoede kan hanteer. In Suid-Afrika, soos in die res van Afrika, neem armoede toe. In plaas van om bloot beskrywend woorde en passasies in die Nuwe Testament wat oor armoede handel, aan die orde te stel, beoog ek om in hierdie voordrag eerder verduidelikend met die tema om te gaan. Dit is my voorneme om die verskynsel van armoede in die Nuwe Testament in konteks te plaas, sodat ons ons eie konteks ' $n$ bietjie beter sal begryp. Die manier hoe ek dit wil doen, is om in die lig van studies oor die verskynsel 'armoedekultuur' die Nuwe-Testamentiese konteks te verduidelik om daardeur aan te toon dat diegene wat gelukkig genoeg was en is om hulle buite 'n 'armoedersltuur' te bevind, geneig is om die oorsake van armoede te oorvereenvoudig en etiketerings om die nekke van arm mense te hang wat veroorsaak dat die voorgestelde remedie soms oorvereenvoudig daar uitsien en selfs halfhartig gedoen word.

My teikengehoor is nie in die eerste plek opgeleide maatskaplike werkers nie, want vir hulle kan ek niks leer nie. Ek het 'voetsoollidmate' van die kerk in die oog wat hulle lewe op die Bybel skoei. My bedoeling is dat ons in hierdie proses sinvol en verantwoordelik met die Bybel sal omgaan wanneer ons riglyne daarin soek met betrekking tot die rol wat ons as Christene teenoor behoeftiges behoort te speel. Wat ek nie beoog nie, is om vandag ' $n$ teologiese uiteensetting van barmhartigheidswerk te bied, en dit sluit in die verhouding tussen Goddelike bevryding en, soos die apostel Paulus (Gal 5:

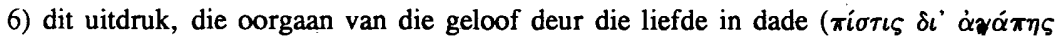

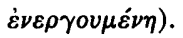

\section{2. 'N BLIK OP DIE HEDE}

Een van die doelwitte van my voordrag is om u weer eens daarvan bewus te maak dat die leefwêreld van die Bybel nie in die multikulturele Suid-Afrika eenduidig toegepas kan word nie. In die eerste plek bevind ons ons almal vandag in 'n industriële wêreld, terwyl die Bybel van 'n voor-industriële tydperk getuig. Sommige van ons is sterk deur ons Europese herkoms beïnvloed en ander van ons deur tradisionele Afrikakultuur. Die leefwêreld van die Bybel het meer ooreenkomste met die tradisionele Afrika-kultuur as met die moderne, verwêreldse Europa en Noord-Amerika. Daarom is dit myns insiens nie moontlik om oor armoede in ons eie tyd vanuit Bybelse perspektief te praat nie sonder om bewus te wees van eerstens die onderskeid tussen die leefwêreld van die Bybel en vandag se industriële wêreld en tweedens die onderskeid tussen die Eerste Wêreld en die Derde Wêreld wat in ons eie midde 'n werklikheid is.

Die terme Eerste Wêreld en die Derde Wêreld word daarom nie negatief as etiketterings gebruik nie. In The Reconstruction and Development Programme van die African 
National Congress (1994:5) word die uitspraak gemaak dat die gebruikmaking van hierdie terme die bedoeling sou hê om apartheid te handhaaf. Dit is nie my pretensie nie. Die Suid-Amerikaanse teoloog, Leonardo Boff, verduidelik die begrip 'Derde Wêreld' - vir die eerste keer deur Franse sosioloë in die vyftigerjare gebruik; met ander woorde vóór die politieke veranderings wat in Oos-Europa en die Unie van Sosialistiese Sowjetrepublieke sedert die begin van die negentigerjare plaasgevind het - soos volg:

It designates those countries that exist on the periphery of the industrialised capitalist world (the USA and Canada, Western Europe, Japan, Australasia, making up the 'First World' and outside the orbit of the socialist countries of Eastern Europe, including the USSR, which make up the 'Second World'

(Boff 1988:3-4)

Volgens Boff is onderontwikkeling die hoofkenmerk van die Derde Wêreld. Hy beskryf dit soos volg: 'economical and technological backwardness, widespread poverty, the existence of authoritarian political institutions, illiteracy and the lack of participation by the people in the processes of society' en wat die godsdiens betref, kerke se afhanklikheid van 'those in the centre for resources, of personnel and funds, and the proliferation of charismatic sects, in which those who feel forsaken take refuge'.

Die situasie wat ons tans in die industriële wêreld aantref, moet teruggevoer word na die oorgang van ' $n$ agrariese na ' $n$ industriële kultuur wat in die Derde Wêréld nog nie voltrek is nie. Hierdie 'oorgang' hou sterk verband met die aard van die soort armoede wat in Suid-Afrika aangetref word - 'n land waar sowel die Eerste Wêreld en dié se industriële kultuur as die Derde Wêreld en dié se agrariese kultuur, asook 'n verwisseling daartussen en vermenging van beide voorkom.

Drie uitvindings in die tweede helfte van die sestiende eeu het, naas die natuurwetenskaplike revolusie, die mense in die Eerste Wêreld laat dink dat hulle selfversorgend en goed is, dat God volledig en wetmatig in tyd en in ruimte deur middel van rasionele proposisies geken kan word en dat die medemens ook ten volle beheers kan word: die marinekompas (die ontdekking van die 'nuwe wêreld', seehandel, kolonisasie), die boekdrukkuns (verspreiding van geletterdheid, bevordering van ideologieë en die aanhelp van gevorderde landboumetodes), en buskruit (relatief klein 'gemeenskappe' verower 'nuwe wêrelde', verkry beheer oor grondstowwe wat ekonomiese ruilhandel finaal in duie laat stort en met kapitalisme vervang). 
Die industriële revolusie van die agtiende eeu het die verwysingsraamwerk van die nawerking van die Moderne Era gedurende die negentiende en twintigste eeu begin vorm. Hierdie revolusie is aangehelp deur die aanwending van die spinwiel, mynbou, die stoomengin, energietegnologie, institusionalisering van wetenskap, en helaas die rekenaartegnologie. Enkele gevolge in 'n tydperk van 200 jaar kan soos volg aangestip word (vgl Lenski, Nolan \& Lenski 1995:270-271): die wêreldbevolking vermenigvuldig sewevoudig ('n groeikoers 15 keer hoër as in die periode sedert die geboorte van Christus tot en met 1750), verstedeliking verhaas (die grootste stedelike gemeenskap in die industrièle periode is ongveer $20 \mathrm{keer}$ groter as die grootste in die agrariese periode), die lewensverwagting is drie keer groter as in die voor-industriële periode, die familie is vir die eerste keer in die mensheidsgeskiedenis nie meer die belangrikste ekonomiese produserende eenheid nie, die rol van die vrou in die ekonomie en die gemeenskap verander radikaal, die jeugkultuur verander as gevolg van kinderarbeid, monargieë verdwyn en die nuwe totstandgekome middelklas verkry toenemende politieke mag, gratis skoolopleiding lei tot die ophef van ongeletterdheid in industriële gemeenskappe, nuwe ideologieë (soos kapitalisme, sosialisme en nasionalisme) kom na vore, die ekonomiese en politieke mag van die kerk word bevraagteken, 'n mondiale kultuur (kleredrag, musiek, taal, tegnologie, organisatoriese patrone soos fabrieke en openbare skole) kom tot stand, wêreldinstellings (soos die VVO, Wêreldhof, ekumeniese liggame) word gevorm, wêreldoorloê vind plaas, sekularisasie neem toe en 'n hierdie-wêreldse nie-transendentale godsdienstige gerigtheid word mode, terwyl daar met veragting neergesien is op die soort godsdienstigheid van 'primitiewe gemeenskappe' en 'ware geloof' dikwels met Europese kultuur geïdentifiseer is.

Hoewel daar nie ontken kan word dat kolonisasie ekonomiese en ander voordele vir Afrika gebring het nie, lyk die situasie vandag nie rooskleurig nie. Reeds aan die begin van die 1990's is bereken dat die wêreld se ekonomiese stelsels 7,5 biljoen Amerikaanse dollars maandeliks toevoeg tot die ongelooflike en werklik ondraagbare skuldlas van 1,500 biljoen dollars waarin die Derde Wêreldlande gedompel is vanweë ' $n$ onsuksesvolle oorskakeling na 'n Westerse ekonomiese stelsel (kyk Küng 1991:2). In Suid-Afrika het die lewenstandaard per persoon sedert die vroeg sewentigerjare tot 1980 sywaarts begin beweeg en daarna met nie minder nie as $11,2 \%$ in die periode 1980 tot 1990 verlaag, en sal welvaart steeds bly daal en werkloosheid toeneem, terwyl die HOP-doelwitte moeilik bereik sal kan word (Ekonomiese Soeklig, Absa Bank, September 1995, in Sake-Rapport 17 September 1995, bl 1). Die produktiwiteitsuitset per werker in 1992 in Suid-Afrika (teen 1990-randpryse) was R34 560 teenoor die Verenigde State van Amerika se R181 660, Frankryk se R127 170, Japan se R125 600, die Verenigde Koninkryk se R94 625 en Singapoer se R84 340. Die Nasionale Produktiwiteitsinstituut het in 1994 daarop gewys dat produktiwiteit in die vervaardigersektor 
gedurende 1975 tot 1992 met 0,6\% per jaar in Suid-Afrika gestyg het in vergelyking met $2,5 \%$ in die VSA, $4,1 \%$ in Japan, $1,7 \%$ in Duitsland, 3,7\% in die Verenigde Koninkryk en 5,8\% in Taiwan. Die werkloosheidsyfer in Suid-Afrika in 1994 was 32,6\% (die syfers styg tot 40-50\% in sekere gebiede). In 1993 het 13,8 miljoen mense die arbeidsmag in Suid-Afrika gevorm, die totale bevolking was 39,3 miljoen (en neem toe met 2,4\% per jaar) en 6,1 miljoen was sonder werk (Backer 1995:8). Meer as 450000 mense sal jaarliks in Suid-Afrika tot die arbeidsmag toetree, 50000 formele werkgeleenthede sal per jaar geskep kan word, $14 \%$ van die werksoekers sal slaag, 'n ekonomiese groeikoers van ten minste $5 \%$ per jaar is nodig om slegs die nuwe toetreders tot die arbeidsmark te akkommodeer, maar die reële groeikoers is minder as 3\%. Armoede sal in Suid-Afrika ongetwyfeld toeneem. Navorsing in 1991 toon aan dat 20$40 \%$ in Soweto onder die broodlyn leef, maar daar is kenners wat meen dat dit eerder nader aan die $80 \%$ is (Gornik 1991:15). Honger, behuisingstekort, werkloosheid, gebrek aan primêre gesondheidssorg, hoë kindersterftes, en swak onderwysgeriewe kenmerk Soweto, terwyl die aangrensende Johannesburg anders daar uitsien. Maar dit is nie veel anders as byvoorbeeld in Baltimore (Virginia) in die VSA nie. Werkloosheid is ook dáár meer as $20 \%$ en andersins is dit 'n stad wat net soos Johannesburg/Soweto 'n mikrokosmos is van 'n groeiende ongelykheid dwarsoor die wêreld tussen ryk en arm (Gornik 1991:16). Na beraming sal daar in die jaar 2000 meer as $20 \%$ van die wêreldbevolking in die stedelike agterbuurtes en plakkerkampe van die Derde Wêreld woon, terwyl 195 miljoen mense wêreldwyd in absolute armoede sal verkeer. Meer as 1000 miljoen mense wêreldwyd oorleef vandag op minder as \$1 per dag (Beeld 11 Augustus 1995, bl 9).

Vir die president van die Wêreldbank, mnr James D Wolfensohn, wat sy pos in Junie 1995 aanvaar het, sal die vermindering van armoede die Wêreldbank se oorheersende doelwit word (New York Times, in Ferreira 1995:9). Lenings vir gesondheid en onderwys het sedert 1990 verdriedubbel tot \$3100 miljoen en na beraming sal dit in die jaar 2000 reeds $\$ 5000$ miljoen beloop. Die doelwit van hierdie lenings is volgens die president van die Wêreldbank om maatskaplike programme te beskerm teen regerings se besparingsmaatreëls en terselfdertyd is dit bedoel om te help dat ' $n$ 'gesonde, geskoolde arbeidsmag' geskep kan word wat buitelandse beleggers tevrede sal stel. Tot so onlangs soos 1990 was die Wêreldbank se lenings en ander amptelike ontwikkelingshulp van $\$ 57900$ miljoen meer as die totale private belegging van $\$ 45000$ miljoen in ontwikkelende lande. Hierdie tendens het sedertdien omgekeer. Private beleggings beloop nou $\$ 179900$ miljoen en amptelike hulp \$54 500 miljoen. Hierdie beleggings is egter tot sekere lande beperk. Afrika suid van die Sahara het minder as $1,5 \%$ daarvan ontvang! 


\section{ARMOEDEKULTUUR}

Vir ons doeleindes is ek geïnteresseerd in wat die uitdrukking 'gesonde' arbeidsmag kan beteken. Myns insiens hou dit verband met wat 'n 'armoedekultuur' behels. Verskillende definisies van armoede in ons tyd is moontlik en almal kom min of meer daarop neer dat dit betrekking het op diegene wat 'underpaid, underfed, underclothed, badly housed and overworked' is (kyk Allen 1970:4). Verskillende invalshoeke lei ook tot korrelerende voorstelle oor remedie: die ekonoom sou byvoorbeeld die nodigheid van meer werkgeleenthede en opleidingsprogramme beklemtoon, die maatskaplike werker sou moontlik die invloed van fisiese en serebrale verhinderings en die rol van hoë ouderdom uitwys en derhalwe die instelling van rehabiliterende dienste beklemtoon, die sosioloog sou op die sosiale instellings van die samelewing wys en die strukturele gevolge wat dit op individue het, terwyl die sielkundige armoede sou verklaar aan die hand van individue se persoonlikheidstrekke. Persoonlik sluit ek by die sosiaalwetenskaplike kultuurantropologie aan, sonder om die waarde van die ander invalshoeke te ontken.

Hoe dit ook al sy, wat belangrik is om te onthou, is dat nie almal wat in armoede verkeer, vrywillig daarin beland het nie, en daarom verraai die etikette wat dikwels aan arm mense gegee word - soos dat hulle mense is wat lui, immoreel, simpel, gelukkig maar onverantwoordelik, slagoffers van hulle milieu - onkunde met betrekking tot wat 'n 'kultuur van armoede' werklik behels. Hierdie saak het te make met sosiale identiteit in terme van 'toegekende' (ascribed) teenoor 'verwerfde' (achieved) sosiale rolle. Dit is ' $n$ insig wat tot die volgende definisie kan lei, naamlik dat 'n arm mens 'experience degraded, negatively valued social identities, as indicated by pejorative labels [kyk Rainwater 1970:10-11] that are frequently applied' (Allen 1970:5). In die lig van hierdie definisie sal die aard van ' $n$ 'program van intervensie' die transformasie behels van 'degraded social identities': 'Hence, to alter social identity it is necessary to change the social organization so that a greater proportion of achieved roles can be enacted by the poor' (Allen 1970:5).

Dit was die Amerikaner Oscar Lewis (1966:19-25) wat die uitdrukking 'armoedekultuur' gepopulariseer het (kyk Sarbin 1970:30). Sy studie is gebaseer op vergelykbare samelewings waar die agtergrond van 'declassed' en 'degraded' mense op soortgelyke historiese antesedente dui en wat waardevolle inligting bied waarmee 'n sosiaalwetenskaplike model ontwerp kan word in terme waarvan nie net dié verskynsel vandag bestudeer kan word nie, maar ook dié in die Nuwe Testament.

Die eerste opvallende aspek is dat daar onderskei kan word tussen respektabele en onrespektabele arm mense. Laasgenoemde tipe mense, indien hulle van die eersgenoemde geostraseer word, sodat hulle verplig word om as 'n selfstandige groep 'n eie oorlewingsstryd te hê, vorm 'n subkultuur wat verband hou met ander subkulture wat nie met armoede as sodanig te doen het nie, soos byvoorbeeld boewery, dwelmhandel, 
satanisme en prostitusie. Ek het nie kennis van die verskynsel 'dwelmhandel' in die leefwêreld van die Bybel nie, maar wel van boewery en prostitusie. Beide sosiale verskynsels het in die Nuwe Testament met 'onrespektabele armoede' te doen.

Om die sosiale identiteit van die 'onrespektabele arme' in die leefwèreld van die Nuwe Testament nader te omskryf is dit vereers nodig om te let op die uitdrukkings wat in die Griekse Nuwe Testament vir arm mense gebruik word. (Wat die Ou Testament betref, kyk o a Brongers 1975: 20-35, en wat die Joodse literatuur [Josefus, Mishna, Tosefta, Gemara's] in die Grieks-Romeinse periode betref, kyk o a Hamel 1990:195-211.)

Die Griekse woord wat die meeste in die Nuwe Testament voorkom, is $\pi \tau \omega \chi o ́ \varsigma$. In die literatuur van ou Griekeland kom die woord $\pi \varepsilon ́ \nu \eta \zeta$ meer voor (Stegemann [1981] 1984:14). Laasgenoemde woord kom in die Nuwe Testament alleen in 'n Ou-Testa-

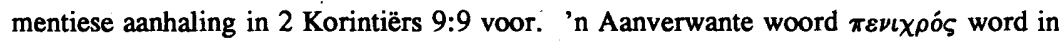
Lukas 21:2 aangetref. Die Joodse historikus, Josefus, verkies om die woord $\alpha$ торо $\varsigma$ te gebruik, maar hierdie woord kom nie in die Nuwe Testament voor nie. In Handelinge 4:34 word die woord è $\nu \delta \varepsilon \eta \dot{\zeta} \varsigma$ aangetref. Verskeie ander uitdrukkings in Grieks word metafories met betrekking tot armoede gebruik, soos byvoorbeeld die woord $\dot{\alpha} \sigma \theta \varepsilon \nu \eta \dot{\zeta}$ (swak/siek wees) in Galasiërs 4:9 (kyk verder Stegemann 1984:15-16). In die Nuwe Testament het die woord $\pi \tau \omega \chi$ ó $\varsigma$ betrekking op die 'onrespektabele arme', die 'desperately poor, wretched creatures who are fighting for their survival' (Stegemann 1984:

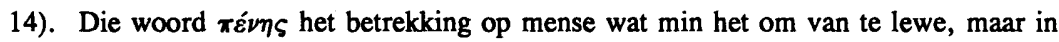
die sin van 'respektabele arm mense'.

Sarbin (1970:31) kom tot 'n besondere gevolgtrekking na aanleiding van studies oor armoede in ons tyd wat myns insiens ook vir ons verstaan van die verskynsel armoede in die leefwêreld van die Nuwe Testament van belang is: die onderliggende dimensie van 'respektabele armoede' is hoofsaaklik ekonomies van aard, maar dié van 'onrespektabele armoede' is meer as net ekonomies van aard deurdat diegene wat tot hierdie kategorie hoort, 'n 'subkultuur' vorm. Interessante studies oor die onderskeidende kenmerke van hierdie 'subkultuur', soos dit in ons eie tyd vorendag kom, is reeds gedoen wat verband hou met meer algemene kategorieë, soos familiale strukture, godsdienstige oriëntasie en sosiale organisering, maar ook met meer besondere sake soos taalgebruik, verstandelike ontwikkeling, tydperspektief en waardesisteme (kyk o a Sarbin 1970:30-42). Vanuit 'n vergelykende kultuur-antropologiese perspektief het dit waardevolle resultate gebied wat in die sosiaal-wetenskaplike eksegese van die relevante gedeeltes in die Nuwe Testament baie bruikbaar is. Die resente artikel van prof Dennis Duling (1995:358-387) in die Hervormde Teologiese Studies ('Matthew and marginality') is 'n voorbeeld daarvan dat teorieë oor hoe gemarginaliseerde groepe ontstaan, ge- 
bruik kan word om die ontstaan van 'n vroeg-Christelike gemeenskap te verduidelik. Ek wil alleen enkele van die resultate van Sarbin se navorsing oor 'armoedekultuur' in hierdie voordrag vermeld.

Wat die perspektief op tyd betref, bevestig navorsing die hipotese dat die 'onrespektabele arme' ' $n$ ongeërgdheid oor die toekoms het wat daartoe aanleiding gee dat daar in 'n armoedekultuur nie vir die toekoms beplan word nie, maar ook dat die hede as onvervuld gesien word. So 'n tydsperspektief bevorder 'n pessimistiese gees. Die taalgebruik in hierdie subkultuur vertoon die kenmerke van 'n ongedifferensieerde sintaksis wat min informasie kommunikeer, maar eerder 'n bestaande sosiale struktuur bevestig. Die feit dat armoedekultuur ' $n$ eie-aardige taligheid vertoon, spruit voort uit die tipe sosiale organisasie waarin mense kultureel ingebed is. Die ongeërgde taalgebruik ('undifferentiated pattern of language') pas in sosiale sisteme wat uitsluitlik rondom persone georganiseer word wie se rolle vooraf bepaal is ('roles-by-ascription'). Daardie sosiale sisteme wat georganiseer word rondom beide persone wat hulle eie rolle bepaal ('achieved roles') en hulle wie se rolle vir hulle bepaal word ('ascriptive roles'), vereis dienooreenkomstig uitgebreide linguistiese sisteme. En wat evaluasiesisteme betref, mense ingebed in 'n armoedekultuur is geneig om te glo dat eksterne kragte en agente uitsluitlik verantwoordelik is vir wat met hulle gebeur en dat beloning nie die produk is van insette op grond van vermoë, dit wil sê interne faktore nie. Laasgenoemde soort mens is derhalwe meer bedag daarop dat die omgewing belangrike inligting oor sy/haar gedrag in die toekoms 'kommunikeer' en sal dus die omgewing ten goede wou beïnvloed. ' $n$ Deterministiese houding by mense in 'n armoedekultuur laat hulle meer blindelings uitlewer aan magie, dobbelary en irrasionele waagstukke. Omdat hierdie mense dikwels nie daarin slaag om te sosialiseer in terme van die gangbare norme nie, etiketteer diegene buite die armoedekultuur die 'onrespektabele arme' met name wat op 'n sosiale identiteit van 'n nie-mens, ofte wel 'n nikswerd ('the social identity of a nonperson'), soos bees, vark, hond, dui. Selfs 'n term soos 'die massa'/ 'die skare' as verwysend na nobodies val in dieselfde pejoratiewe benamings en is 'n aantasting van menswaardigheid (Sarbin 1970:39). Die volgende slotwoorde in die artikel van Theodore Sarbin (1970:44; my beklemtoning) behoort daarom onthou te word:

If we have learned anything ... it is that direct efforts to modify the effects of immersion in the culture of poverty have negative utility. Providing free dictionaries, clocks, and calendars to the ghetto resident does not guarantee changes in linguistic competence or temporal orientation. Kindness, charity, welfare or threat of punishment have no effect 
unless the degraded person is first removed from the status of nonperson. To do this, the system must allow every participant some measure of choice through access to achieved roles.

Bogenoemde studies met betrekking tot 'n armoedekultuur kan sinvol dien as hipotese vir ' $n$ ondersoek na ' $n$ vergelykbare subkultuur in die leefwêreld van die Nuwe Testament. Hoewel ons nie dokumente in die Nuwe Testament aantref wat deur sosiale uitgestotenes self geskryf is nie, kan navorsing oor aspekte soos tydsperspektief en evaluasiesisteme interessante resultate lewer, indien dit toegepas word op die groep wat ons in die Nuwe Testament as ingebed in die kultuur van armoede identifiseer. In hierdie verband kan daar byvoorbeeld nuwe lig op die Nuwe-Testamentiese getuienis oor natuurrampe gewerp word (vgl Stephan Joubert 1987:69-72).

Hierdie studie het egter hoogstens die bedoeling om daardie groep in die Nuwe Testament te identifiseer wat in armoedekultuur ingebed is, aan te toon dat hulle nie as bloot ekonomiese behoeftiges gesien moet word nie en dat hulle 'bevryding' die transformasie van hulle identiteit van 'nikswerd' (nonpersons) veronderstel. My suggestie is dat ons self in die kerk vandag, in ons bestryding van armoede, by so 'n transformasie moet begin. Daarom die volgende vrae: wie in die leefwêreld van die Nuwe Testament is die 'onrespektabele' arm mense?, wat is hulle identiteit?, en na watter identiteit transformeer die evangelie hulle?

\section{DIE ONRESPEKTABELE PERSOON ('NONPERSON') IN DIE VOOR- INDUSTRIËLE LEEFWÊRLD VAN DIE NUWE TESTAMENT}

'n Mens kan enige samelewing bestudeer in terme van deelwêrelde (Malina 1987:354366). Die ekonomie is só 'n verwantskap waar mense as 'n groep op 'n kollektiewe wyse materieel bevoorreg of verontreg word. Natuurlik kan sodanige bevoorregting of verontregting die gevolg wees van die individu in die groep se eie vermoë of onvermoë. Naas die ekonomie vorm die politiek ook 'n sosiale verwantskap waar heersers en onderdane in terme van mag en kollektiewe organisasie voortbestaan. Die familie vorm ook 'n sosiale verwantskap. Hier funksioneer aspekte soos geboortelike afkoms en nasionaliteit as sosiale kragte wat 'n bydrae lewer tot lojaliteit, konsolidariteit en toegewydheid. Kollektiewe organisering op hierdie terrein kan, maar hoef nie, ekonomies en/of politieke gevolg te hê nie. Godsdiens is ook iets wat 'n sosiale groepsdimensie het. Godsdiens as 'n sosiale verwantskap verskaf in 'n groot mate die waardes of minstens die gewete wat sake aanspreek met betrekking tot familie-aangeleenthede en nasionaliteit, politiek en ekonomie. Dit beteken egter nie dat godsdiens in alle 
kulture en samelewings die botoon voer nie. Enigeen van bogenoemde vier deelwêrelde kan die oorkoepelende een wees en die ander is dan daarby op 'n ondergeskikte wyse ineengeskakel. In samelewings wat deur totalitaristiese regimes beheer word, oefen politici mag en politieke kontrole uit oor 'bloed-en-bodem' sake, sowel as oor die godsdiens en die ekonomie. Politiek het te doen met die verkryging van mag en die handhawing daarvan. Hoewel dit in 'n groot mate so is dat politiek vandag in die hele Westerse wêreld feitlik alles beheer, moet ons ons steeds daaraan herinner dat dit nie altyd en oral so gewees het nie. Minstens godsdienstige mense moet onthou dat alles tog nie polities of ekonomies van aard is nie. Die moontlikheid moet wel oopgehou word dat die ekonomie in sterk kapitalisties georiënteerde lande die onderliggende ideologiese krag kan wees. Daar is egter ook samelewings waar families en die hoofde van families die kontrole uitoefen. In sulke samelewings is die ekonomie, politiek en godsdiens ingebed in 'n sosiale verwantskap wat primêr deur geboorte en nasionaliteit bepaal word.

Wanneer ' $n$ mens na die samelewing bestaande uit verskillende sosiale verbande as deelwêrelde kyk en 'n mens stem saam dat hulle as ideologiese kragte kan funksioneer, dan sal daar begrip vir die standpunt wees dat die uitdrukking 'onrespektabele arme' telkens in terme van die onderskeie situasies op iets anders betrekking kan hê. In sekere samelewings kan hulle die behoeftiges wees, omdat hulle die ekonomies ondergeskiktes is. Dit is ook moontlik dat die 'onrespektabele' in 'n ander situasie weer op die verdruktes kan dui, omdat hulle polities verontreg word. In terme van die familieen nasionaliteitsverwantskap kan die kinderloses, die melaatses en die vreemdelinge die sosiaal uitgestotenes wees. Maar dit kan ook die 'ongelowige' in die religieuse sin van die woord wees. Die vraag is, wat het dit ingehou om as die 'onrespektabele arme' in die leefwêreld van die Nuwe Testament geklassifiseer te word?

Om ryk of arm te wees is nie net onderskeidings wat op die industriële samelewing betrekking het nie. In die voorindustriële wêreld van byvoorbeeld die Nuwe Testament het 'n mens uiteraard ook ryker en armer klasse van mense aangetref. Dit is ook so dat hoe meer die agrariese samelewing weg van die hortikulturele situasie (akkerbou vór die ontdekking van die ploeg) ontwikkkel het, hoe duideliker het die verband tussen sosiale status en rykdom geword. In so 'n ontwikkelde agrariese konteks (soos dié van die Nuwe Testament) was die ekonomiese en sosiale klassesisteem egter steeds deel van die grotere sosiale sisteem waar familiale status belangriker was. Op die oppervlak kan dit dus lyk of politieke posisies en geld as statussimbole geag is. Dieperliggend egter het familiale strukture aanleiding tot bepaalde status gegee wat weer tot politieke mag en rykdom gelei het (kyk Horsley 1995:196). Die wyse waarop die aristokrasie (adelklas) in 'n agrariese samelewing spontaan gevorm en gefunksioneer het, het die aard 
van die klassesisteem in die eerste-eeuse Mediterreense wêreld bepaal. Wat die aristokrasie betref, het geboortelike herkoms en familiale belange 'n sterker ideologiese rol vervul as wat sigbaar was op die oppervlak van die samelewing wat deur wette en regulasies georden is (kyk Van Aarde 1993:526). Die aristokrasie as sodanig as groep het nie enige politieke mag of wettige status in die agrariese samelewing gehad nie. Die mag wat hulle besit het, is daaraan toe te skryf dat hulle ' $n$ bepaalde statusgroep was. Sosiale status het in 'n agrariese samelewing (baie meer as in vandag se geindustraliseerde konteks) tot mag en rykdom gelei. Klas gebaseer op rykdom was minder belangrik as sosiale status, omdat status (en nie klas nie) gewoonlik langdurige politieke mag en daarmee saam rykdom in die hand gewerk het. Om tot die aristokrasie te behocrt het dus sosiale status bepaal. Hoewel die dominante rol van familiale strukture binne die konteks van die ontwikkelde agrariese samelewing, soos byvoorbeeld die eiesoortige organisasie van die 'uitgebreide familie' (die beth-av) in 'n bepaalde dorpie as 'n geslote eenheid (close unit), in 'n sekere sin stadigaan aan't verdwyn was (kyk Fiensy 1991:132), het die aristokrasie steeds die onderliggende dominante sosiale struktuur gevorm. Hierdie dominante posisie het politieke mag en materiële besit moontlik gemaak.

So gesien, het familiale strukture as die versweë 'ideologie' gefunksioneer terwyl brute politieke en juridiese mag (soos die Romeinse imperialisme) op die oppervlak die septer geswaai het. 'n Mens kan dit vergelyk met die rol wat die ekonomie in die twintigste eeu in die sogenaamde ontwikkelde lande van die Eerste Wêreld inneem. In sulke 'demokratiese' lande het politiek as ' $t$ ' ware alles geword en is dit politici wat mag oor die lewe van mense uitoefen. Politieke posisies is derhalwe ook statussimbole. Tog vorm die ekonomie die dominante struktuur waarvan die politikus se sukses grootliks afhankix is. Hoewel politieke maghebbers nie noodwendig die rykste mense in die samelewing is nie, bepaal ekonomiese kragte die uitvoerbaarheid van die politikus se beleid. Om dus tot 'n politieke magsposisie verkies te word in 'n demokratiese land, soos die Verenigde State van Amerika, eis 'n beleid wat ekonomiese welvaart in die hand kan werk. Die sogenaamde 'brood en botter' sake bepaal met ander woorde of die bevolking iemand tot ' $n$ politieke magsposisie sal verkies of daarvan sal onttroon. Die ekonomie maak dus die 'valse bewussyn' uit en bepaal ook sosiale status in die samelewing. In die eerste-eeuse Mediterreense wêreld was dit egter nie die ekonomie wat die dominante instelling in die samelewing gevorm het nie, maar die familie. Status is dus bepaal deur burgerskap en familie. Rykdom was belangrik vir mense wat in 'n hoë klas beweeg het, maar rykdom kon hulle nie daardie hoë status gee nie. In teenstelling hiermee kon sosiale status iemand deel maak van 'n hoë klas waar rykdom en mag bekom kon word. Status en mag was dus belangriker as rykdom (kyk Malina 1993:105-106). 
Om saam te vat: Die inwoners van Palestina het gedurende die eerste eeu in 'n ontwikkelde agrariese samelewing geleef wat deel was van 'n groter agrariese, burokratiese en gedeeltelik gekommersialiseerde aristokratiese ryk. Dit was 'n oorgangstydperk toe geld in die vorm van muntstukke simboliese waarde begin kry het en die besit, versameling en redistribusie daarvan uitdrukking van eer/prestige en mag begin word het (kyk Stegemann \& Stegemann 1995:45-47). Ons moet egter onthou dat simboliese waardes in 'n dialektiese verhouding met sosiale waardes soos familiale en politieke belange staan. Godsdienstige waardes was in die eerste-eeuse Mediterreense wêreld hierby ingebed. In 'n ontwikkelde agrariese samelewing het dit begin gebeur dat eeren-skande (wat met hierdie familiale, politieke en godsdienstige waardes te doen het) ook deur geld - wat simboliese uitdrukking van eer en mag begin word het - bepaal is. En dit het veral te doen gehad met wie geld besit, hoe dit en van wie dit bekom en aan wie en hoe dit weer uitgedeel is.

In vergelyking met die vroeëre hortikulturele samelewings het die agrariese samelewing meer gevorderde boerderymetodes, veral die ploeg, aangewend. Groter bevolkings het begin voorkom. 'n Groter landbousurplus is geproduseer en 'n groter en meer dominante leiersklas het vorendag getree wat beter georganiseerd was en meer gesentraliseerd aangetref is (kyk Lenski, Nolan \& Lenski 1995:175-222). Anders as die later industriële samelewings is die agrariese samelewing gebaseer op die landbou terwyl die handel 'n kleiner rol speel. Rykdom en mag is oneweredig verdeel en was in die hande van 'n klein groepie mense. Sosiale klasse is streng hiërargies georden (kyk Fiensy 1991:158). Eintlik word net twee klasse aangetref. Aan die een kant was daar die werkers/boere/arbeiders (kyk Van Aarde 1994:96). Hulle het die voedsel en middele geproduseer wat vir die samelewing nodig was. Aan die ander kant was daar 'n klein elite leiersklas wat in 'n soort beskermheerposisie as patrons die eersgenoemde klas as clients teen aggressie van buite beskerm het. 'n Mens kan hierdie verhouding tussen die elite en die nie-elite beskryf as ' $n$ verhouding tussen ' $n$ beskermheer/ weldoener en 'n onderdaan/afhanklike. Vanuit 'n ekonomiese hoek gesien, berus hierdie patronaatskap op die beginsel van 'gee-en-ontvang', ofte wel 'resiprositeit' (kyk Pilch \& Malina 1993:134-135). Die elite het geleef van die landbousurplus wat die boere geproduseer het. Aan die ander kant was dit deel van die sosiale rol van die elite om die boere te beskerm sodat hulle ongestoord die oorskotte kon produseer. Oorskotte het bestaan uit middele soos plaasprodukte, klere en eenvoudige gereedskap en implemente. Die feit dat ' $n$ weldoener in die samelewing eer ontvang, is dus bepaal deur die feit al dan nie of hy/sy sy/haar rol as beskermheer teenoor sy/haar afhanklike vervul het. Vanuit die perspektief van resiprositeit voorsien die 'beskermheer' beskerming in ruil vir eerbetoning deur die 'onderdaan' wat oorskotte produseer (somtyds 
deur die belastingstelsel daartoe verplig - kyk Fiensy 1991:100-101;). Die patron, gewoonlik ' $n$ afwesige landheer (kyk Matthews 1991:250; Horsley 1995:207-221)) leef van die surplus, maar is ook weer verplig om aan hulpbehoewendes in die samelewing uit te deel. Ekonomiese redistri-busie berus dus op die beginsel van providentia wat weer ingebed is in die beginsel van resiprositeit. 'n Weldaad deur 'n patron skep 'n ketting van verpligtinge: die client as ontvanger het die verpligting om deur middel van eerbetoning op die gawe te reageer wat die patron weer onder verpligting van verdere versorging plaas. Deel van die verpligte lojaliteit wat 'n client teenoor sy patron binne Romeinse politieke strukture moes betoon, was om onder andere die weldoener se belange in die politiek te bevorder. Tog was die onderskeie leefwêrelde van die elite en die nie-elite ver van mekaar verwyderd.

Surplusse was egter nie altyd spontaan geproduseer nie, omdat die boere geneig was om net genoeg vir eie gebruik te produseer. Daarom moes die elite somtyds gebruik gemaak het van veral belasting om die boere sover te kry om oorskotte te produseer. Belasting op oeste was ongeveer $30-70 \%$. Hierdie feit het tot ernstige sosiale krisisse in die eerste eeu op Palestynse bodem bygedra. Ons moet onthou dat die eerste-eeuse Mediterreense samelewing beskryf kan word as 'n situasie waarin dinge van waarde slegs beperk beskikbaar was (kyk Malina 1993:90-116). Dit het in die eerste plek eer en prestige gegeld, en die simbole hiervan. Dit was vir min in die samelewing beskore om status te beklee en derhalwe as eervol gebore te word of om eer te verwerf. Nie net was eer dus 'n limited good nie, maar ook die ander sake in 'n ontwikkelde agrariese konteks wat op die oppervlak van die samelewing as simbole van eer begin funksioneer het.

Daar was nege belangrike subklasse in die agrariese samelewing (kyk Van Aarde 1994:99-101; Stegemann \& Stegemann 1995:70-74): vyf wat deel was van die elite en vier wat deel was van die laer klas. Dit was nie die enigste subklasse wat voorgekom het nie, maar wel die belangrikstes wat die sosiale stratifikasie van die ontwikkelde agrariese samelewing uitgemaak het. Bo-aan die leer was die leiers en die regerende klas. Hulle was diegene met baie mag en grond, en het al die klasse beheer deur belasting. Die regerende klas was omtrent $1-2 \%$ van die bevolking, bestaande uit aristokrate (gebore uit adelike families) en aangestelde burokrate. Sterk leiers het gewoonlik hierdie persone aangestel. Hierdie posisies kon ook gekoop word. Politieke mag het rykdom voorafgegaan en nie andersom nie. Gewoonlik het rykdom op politieke mag gevolg en het die verlies aan rykdom gedui op die reeds bestaande verlies aan politieke mag. Van die priesterhoofde het onder hierdie klas geval asook van die groot grondbesitters, erkende familiehoofde (= 'oudstes') en belangrike amptenare. Die ondersteunende klas (retainers) het ongeveer 5\% van die bevolking uitgemaak. Hulle het die 
soort lewe van die elite gedeel, maar nie die mag gehad nie. Godsdienstige leiers in Jerusalem, soos die hoëpriester, priesterhoofde en familiehoofde wat die lede van die Sanhedrin gevorm het, kan as behorende tot hierdie klas beskou word. Indien die regerende klas nie baie sterk was nie, of die land regeer is deur militêre owerhede (wat ook in hierdie klas geval het), was die godsdienstige leiers taamlik gesagvol. As die ondersteuende klas was hulle afhanklik van die rykdom en gawes van die regerende klas. Hulle was met ander woorde nie net ambagsmanne soos sommige geleerdes vroeër gemeen het nie. Status het in elk geval die belangrikste rol gespeel en nie rykdom nie. Die handelaars het hulle in 'n posisie tussen die hoër en laer klasse bevind, omdat die leiers en regerende klas hulle goedere nodig gehad het. Die priesters was soos die ondersteunende klas afhanklik van die regeerders. Die leiers van die priesters was soms deel van die regerende klas en het somtyds groot rykdom besit omdat hulle die tiendes hanteer het. Hierdie rykdom was egter relatief, omdat die regerende klas dit kon opeis indien hulle sou wou. Hulle het sterk met die regerende klas vir mag gekompeteer en het in hierdie wedywering hulle daarop beroep dat hulle 'n 'ander' outoriteit gehad het wat nie van hierdie wêreld was nie. Die kleinboerderygemeenskap (peasants) was die grootste deel van die bevolking. Hulle het landerye verbou en handewerk verrig. Die ambagslui het geen mag gehad nie en was slegs belangrik waar die regerende klas hulle dienste nodig gehad het. Die agste subgroep was die sogenaamde 'onreines'. Hierdie mense was geag om slegs goed te wees om onrein werk, soos leerlooiery en werk in myne, te verrig. Die laaste groep is die 'onrespektabeles' (expendables). Hierdie klas wat ongeveer $5-10 \%$ van die bevolking uitgemaak het, is feitlik geen plek in die samelewing gegun nie. Hulle het hulle dikwels tot roof en ander onwettige aktiwiteite gewend. Baie van hulle was aanvanklik lede van die kleinboerderygemeenskap wat hulle grond verloor het of ambagslui wat om een of ander sosiale ostraserende rede nie hulle beroep kon beoefen nie.

Soos die samelewing al hoe meer gedifferensieerd en gestratifiseerd geword het, het verskillende patron-client groeperinge naas die gewone politieke en sosiale groepe tot stand gekom. Op die oppervlak van die samelewing het geboorte en die behorendheid tot ' $n$ bepaalde familie nie meer ' $n$ rol in baie van hierdie groepe gespeel nie, hoewel hulle hulle in fictive kinship-organisasie gegroepeer het - 'n aanduiding dat die familie as instelling steeds die onderliggende ideologie gevorm het. Lede van sulke 'denkbeeldige families' is deur ' $n$ gemeenskaplike doel of binding aan ' $n$ beskermheer met mekaar verbind. Hierdie 'gemeenskap' word in die Nuwe Testament (binne die

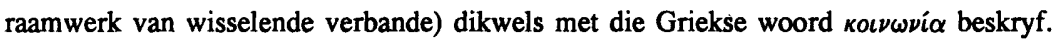
Grondliggend aan die band met mekaar as gevolg van 'n gemeenskaplike binding aan 'n derde party, is dus ' $n$ bepaalde solidariteit en sosiale funksionering geleë. 


\section{GEVOLGTREKKING}

Die Nuwe Testament is gedurende die Hellenistiese periode in die gebied oos van die Middelandse See geskryf. Die hedendaagse sosiaal gestruktureerde teenstelling tussen arm en ryk is nie tipies van wat as soortgelyk in die Nuwe Testament beskou kan word nie. Om 'arm' in die Bybelse tydperk te wees, is byvoorbeeld nie noodwendig dieselfde as om ekonomies 'arm' te wees nie. Met ander woorde, as daar in die Bybel verwys word na die 'arme' Saggeus, dan is hy nie noodwendig 'n persoon wat nie geld gehad het nie. Só 'n 'arme' was waarskynlik iemand wat sy/haar posisie nie kon handhaaf as ongelukkige omstandighede hom/haar en sy/haar familie oorval nie. Hierdie omstandighede kon skuld behels, ballingskap in 'n vreemde land, siekte, dood van 'n eggenoot of een of ander persoonlike fisiese gebrek. Hierdie soort ongeluk is gesien as geïnstigeer deur Satan en sy agente. Wat die 'armes' betref, is dit duidelik dat hulle nie beskou moet word as ' $n$ sosiaal gestruktureerde klas nie. Daarom is dagloners, lede van die kleinboerderygemeenskap sonder grondbesit, bedelaars ensovoorts nie opsigself die 'armes' nie. Die 'armes' is nie as sodanig 'n ekonomiese kategorie nie. Die alternatief van die 'arme' is derhalwe ook nie noodwendig die 'ryke' nie. 'n 'Arme' kon iemand onder die ekonomies ryk aristokrate of die ondersteuende klas gewees het, soos Saggeus in Lukas 19:1-10, omdat hy 'n 'sondaar', ofte wel 'n 'verlorene', genoem is.

Wanneer ons die 'sosiaal-uitgestotenes', ofte wel die 'onrespektabeles', wel as die 'armes' defineer, doen ons dit in die sin van iemand wat binne die sosiale konteks van die leefwêreld van die Nuwe Testament nie in staat was om sonder barmhartigheidsondersteuning voort te bestaan nie (kyk Van Aarde 1988:829-846). Dit kon die 'arme' weduwee wees (Luk 21:1-4) wat net twee kopergeldstukke gehad het en ook die 'arme' bedelaar by die ryk man se hek (Luk 16:19-21) wat net soos die stom, verlamde en blinde, nie in staat was om enige terugbetaling te maak aan diegene wat vir hulle gehelp het nie. Maar dit kon ook Levi, die tollenaar as lid van die aristokrasie se 'ondersteuners', wees wat 'siek' was en 'n dokter nodig gehad het (Luk 6:27-32), of die Herodiaan, die Galilese regeringsamptenaar, wie se seun sterwend was (Joh 4:43-54) of die 'ongelowige' Griekssprekende Siro-Fenisiese vrou met die 'duiwelbesete' kind (Mark 7:24-30) wat die oorskiet brood nodig het wat van die eettafel afval en wat die hondjies normaalweg kry. Sulke mense is die mense, soos diegene in die Psalms, wat in nood is en hulle kommer voor God bely, want God is hulle enigste beskermer.

In die lig van ons konstruksie van die sosiale konteks van die leefwêreld van die Nuwe Testament, het dit geblyk dat die 'onrespektabele arme' kon voorkom onder die aristokrate en die politieke maghebbers, sowel as onder diegene wat tot die laer klasse soos die grondlose kleinboerderygemeenskap behoort het. In die sinoptiese evangelies 
kan agtien tipe 'ongelukkige' mense as die sosiaal-veragtes in terme van 'onrespektabele armes' met wie Jesus bemoeienis gehad het, onderskei word (kyk Hollenbach 1987:50-63). Hulle 'ongeluk' was die gevolge van of 'natuurlike' oorsake of sosiale omstandighede. Die meeste was siek mense of gestremdes, te wete blindes (Luk 4:18; Matt 11:5; Luk 14: 13, 21), verlamdes (Matt 11:5; Luk 14:13, 21), melaatses (Matt 11:5; Luk 16:19-31), dowes (Matt 11:5), en siekes in die algemeen (Matt 25:31-46). Hierdie groep vorm ses van die gemelde agtien tipe 'onrespektabele arm mense'. Dertien vorm 'n kategorie wat verband hou met ontworteling met betrekking tot familieaangeleenthede, te wete die treurendes (Matt 5:3vv), hongeriges (Matt 5:3v; 25:31-46; Luk 16:19-31), dorstiges (Matt 5:3vv; 25:31-46); melaatses (Matt 11:5; Luk 16:1931); dowes (Matt 11:5), dooies (Matt 11:5), verlamdes (Luk 14:13, 21), weduwees (Mark 12:42-43); huisloses (Luk 16:19-31), bedelaars (Luk 16:19-31; Matt 25:31-46), vreemdelinge (Matt 25:31-46), naaktes (Matt 25:31-46) en siekes in die algemeen (Matt 25:31-46). Vyf vorm 'n kategorie wat met ekonomiese probleme te doen het, te wete die hongeriges', dorstiges, huisloses, bedelaars en dié sonder klere. Slegs vier groepe van die 'onrespektabele arm mense' kan volgens Hollenbach (1987:55) op een of ander manier met politieke mag (mis)bruik in verband gebring word, te wete die gevangenes (Luk 4:18; Matt 25:31-46), onderdruktes (Luk 4:18), sagmoediges (Matt 5: $3 v v$ ) en die melaatses. Vir hierdie 'onrespektabeles', diegene onder die aristokrasie én onder die kleinboere, Jode én nie-Jode, het Jesus getoon en geleer hoe om te midde van neerdrukkende omstandighede op God se teenwoordigheid staat te maak. Hierdie teenwoordigheid is beleef in terme van die geloofsgemeenskap as ' $n$ 'denkbeeldige famnie'.

Watter riglyne bevat hierdie studie van armoedekultuur in die leefwêreld van die Nuwe Testament vir die kerk om die vraagstuk rakende dié subkultuur in Suid-Afrika vandag op ' $n$ verantwoordelike wyse te benader? In 'n Christelike geloofsgemeenskap waar gesindheid en optrede op die evangelie van Jesus Christus gebaseer word, behoort die kerk die ruimte te wees waar die 'onrespektabele arme' se identiteit getransformeer vanaf 'n nikswerd, 'n nie-persoon ('nonperson') tot kind van God. In hierdie 'huishouding van God' word daar nie net van brood geleef nie, maar van genade, en diegene wat begenadig is, begin as mekaar se 'beskermhere' op te tree. Dit is die 'transformasie' en 'identiteit' waarvan daar in die kerk gepraat behoort te word!

\section{Literatuurverwysings}

African National Congress 1994. The Reconstruction and Development Programme: A policy framework. Johannesburg: Umanyano Publications.

Allen, V L (ed) 1970. Psychological factors in poverty. New York: Academic Press. (Institute for Research on Poverty Monograph Series.) 
Allen, V L 1970. Theoretical vantage points: Introduction, in Allen 1970:3-7.

Backer, L 1995, Arbeidsmag buk swaar onder werkloosheid, Sake-Rapport 17 September 1995 , bl 8 .

Brongers, H A 1975. Rijkdom en armoede in Israel. Nederländs Theologisch Tijdschrift 29, 20-35.

Duling, D C 1995. Matthew and marginality. HTS 51/2, 358-387.

Ekonomiese Soeklig, Absa Bank, September 1995, in Sake-Rapport 17 September 1995 , bl 1.

Ferreira, B 1995. 'Wêreldbank verstel Derde Wêreld-fokus'. Beeld 11 Augustus 1995, bl 9.

Fiensy, D A 1991. The social history of Palestine in the Herodian period: The land is mine. Lewiston: Edwin Mellen Press. (Studies in the Bible and Early Christianity 20.)

Hamel, G 1990. Poverty and charity in Roman Palestine, first three centuries $C$ E. Berkeley: University of California Press.

Hollenbach, P 1987. Defining rich and poor: Using social sciences, in Richards, K H ed, SBL 1987 Seminar Papers, 50-63. Atlanta: Scholars Press.

Gornik, M R 1991. The rich and the poor in Pauline theology. Urban Mission, September 1991, 15-26.

Horsley, R A 1995. Galilee: History, politics, people. Valley Forge, Pennsylvania: Trinity Press International.

Joubert, S J 1987. Die armoedeprobleem van die Jerusalemgemeente: 'n Sosio-historiese en eksegetiese ondersoek. DD-proefskrif, Universiteit van Pretoria.

Küng, H 1991. Global responsibility: In search of a new world ethic, translated by $\mathbf{R}$ Piper. New York: Crossroad.

Lenski, G, Nolan, P \& Lenski, J [1970] 1995. Human societies: An introduction to macrosociology. Seventh edition. New York: McGraw-Hill.

Lewis, O 1966. The culture of poverty. Scientific American 215, 19-25.

Malina, B J 1987. Wealth and poverty in the New Testament and its world. Interp. 41, 354-366.

1993. The New Testament world: Insights from cultural anthropology. Revised edition. Louisville: Westminister.

Matthews, V H [1988] 1991. Manners and customs in the Bible: An illustrated guide to daily life in Bible times. Revised edition. Peabody, MA: Hendrickson.

Pilch, J J \& Malina, B J 1993. Biblical social values and their meaning: A handbook. Peabody, MA: Hendrickson.

Rainwater 1970. Neutralizing the disinherited: Some psychological aspects of understanding the poor, in Allen 1970:9-28. 
Sarbin, T R 1970. The culture of poverty, social identity, and cognitive outcomes, in Allen 1970:29-46.

Stegemann, W [1981] 1984:14, The gospel and the poor, translated by Dietlinde Elliott. Philadelphia: Fortress.

Stegemann, E W \& Stegemann, W 1995. Urchristliche Sozialgeschichte: Die Anfänge im Judentum und die Christusgemeinden in der mediterranen Welt. Stuttgart: Kohlhammer.

Van Aarde, A G 1988. Jesus en die sosiaal-veragtes. HTS 41, 829-846.

1993. Aspekte van die sosiale stratifikasie van die ontwikkelde agrariese samelewing in die eerste-eeuse Palestina. HTS 49/3, 515-545.

1994. Kultuurhistoriese agtergrond van die Nuwe Testament: Die eerste-eeuse Mediterreense sosiale konteks. Pretoria: Kital. 